\title{
Sadece Bir Yıldız Kaydı, Tabii ki Son Değil...
}

\section{Only One Shooting Star, Of Course Not the Last...}

\section{Erkan Erhan*}

$\ddot{\boldsymbol{O}} \boldsymbol{z}$

Sınıf arkadaşım Neslihan'ın vefatı benim için bir yıldızın kayması gibiydi, dünya döndükçe kayacak daha çok yıldızlar olacağl için elbette bu son yıldız kayması olmayacak.

Anahtar Sözcükler: Neslihan Güler; Türk kütüphaneciliği; Milli Kütüphane; Hazine ve Maliye Bakanliğl Kütüphanesi.

\begin{abstract}
The death of my classmate Neslihan was like a shooting star for me. Of course, this will not be the last shooting star as there will be more stars to shoot as the world turns.

Keywords: Neslihan Güler; Turkish librarianship; National Library of Turkey; Library of Treasury and Finance Ministry.
\end{abstract}

Her zamanki gibi kimseyi rahatsız etmek istemediğinden olsa gerek, ancak vefatından bir gün önce öğrendim rahatsızlığını. Endişeli bekleyişimiz ve iki günlük çırpınışımıza rağmen 18 Nisan'da kaybettik sevgili arkadaşımız Neslihan'1. 20 Nisan'da Tayfun arkadaşımızın WhatsApp Grubumuzda paylaştığı, Neslihan için anı mektubu yazma düşüncesini görünce, ben de hemen bir şeyler yazmam gerektiğini düşündüm.

Ancak, bir süre kendimi zorlasam da ne nasıl bir şey yazmam gerektiğini bulabildim ne de nereden başlayacağımı. Zira, aynı bölgeden olmamızın da etkisiyle neredeyse 40 yıllık oldukça yakın bir arkadaşlığımız var. Daha arkadaşımın kaybını kabullenememişken oturup bir şeyler yazmak çok zor geldi.

Sonunda ilk aklıma gelen birkaç cümleyle Neslihan'ı anmaya karar verdim.

Hacettepe Üniversitesi Kütüphanecilik Bölümünde başlayan arkadaşlığımız, Hacettepe Üniversitesi Beytepe Yurtları'nda ve arkadaş çevremizde pekişti. Doğal olarak 4 yıl göz açıp kapayana kadar geçti ve mezun olup evimize döndük. Bu arada birbirimizin ailesini görme, tanıma firsatı bile bulmuştuk.

Kütüphaneciler için en büyük işveren olan Kültür Bakanlığı sınav açmadığ 1 için bir süre vekil öğretmenlik gibi işlerde çalıştığını hatırlıyorum.

Her ne kadar haberleşiyor olsak da ne tesadüftür ki yollarımız bu kez Milli Kütüphane'de kesişti ve dostluğumuz burada da devam etti. Milli Kütüphane'de ayrı bölümlerde olsak da

\footnotetext{
* Kültür ve Turizm Bakanlığı Telif Hakları Genel Müdürlüğü. E-posta: erkan.erhan@ gmail.com Ministry of Culture and Tourism.E-mail: erkan.erhan@gmail.com
}

Geliş Tarihi - Received: 27.05.2021

Kabul Tarihi - Accepted: 02.06.2021

Yayımlanma Tarihi - Published: 30.06.2021 
yakın çalışma arkadaşı olduk. Güneydoğu Anadolu Projesi çerçevesinde 3 haftalığına bölgeye giden grubun içerisinde yer alarak başarılı bir sergi ve tanıtım çalışması gerçekleştirdik.

Bir akşamüstü Milli Kütüphane'deki odasına ziyarete gitmiştim, ısrarla canı pasta istediğini söyledi. Her zamanki takılmalarından biri olduğunu düşünerek "Bu saatte o da nereden çıktı, çok istiyorsan mesai bitince gider yeriz, acelen ne?" dedim. "Arkadaşım; bazı şeylerin saati olmaz." deyip nedenini anlattı gözleri parlayarak. İşte orada haberim oldu bebek beklediğinden, Doğa'dan.

Daha sonra Milli Kütüphane'den ayrıldı ama gittiği Hazine Müsteşarlığı Kütüphanesi Milli Kütüphane'ye yakın olduğu için her zaman görüştük.

Her durumda haberleştik Neslihan ile, taa ki kaybetmeden 15-20 gün öncesine kadar. "Sevim arkadaşımız ile beraber bir yerde buluşalım, sıkıldım bu COVID-19 sürecinden. Bir gün ayarlayayım arayacağım.” demişti telefonda. Kronik rahatsızlıkları nedeniyle kendini korumaya çalıştığını, çeşitli vitaminler aldığını söylemişti. Ama gerçekleştiremedik...

40 yıldır tırnaklarıyla kazıyarak yaşadığı Ankara'da, hâlâ tırnaklarıyla kazıyarak tutunmaya çalışıyordu Neslihan. Bunu oğlu Doğa için başarmıştı.

Herkesin yaşamında çalkantılar vardır elbette, ama Neslihan'ın yaşadıklarını düşündüm de özel yaşamında ve iş yaşamında yaşadığı kısır çekişmeler ve aldığı darbeler çok yıpratmıştı. Yakın olmamıza rağmen, kimseye muhtaç olmadan yaşamayı ilke edinmesi nedeniyle arkadaşlığımızı hep sorunlarından uzak tuttu. Herkese yardım etmek isterken, yardım istemeden yaşamını sürdürmeye çalışması en büyük özelliğiydi bence. Belki de bu yüzden, rahatsız olduğunu bile kimseye söylemeden sessiz sedasız aramızdan ayrılıp gitti. Sadece bir yıldız kaydı, tabii ki son değil...

Gittin çok sevdiğin Küçükkuyu'ya bir sabah vakti, sanki zeytinlik ile ilgilenip dönecekmiş gibi...

Huzur içinde uyu sevgili arkadaşım. 